\title{
Intramural hematoma of the colon after polypectomy - an unusual case occurrence
}

A 43-year-old man was admitted to our hospital for polypectomy because of multiple colonic polyps. He had no history of hemorrhage or abdominal trauma, and was not being treated with anticoagulant therapy. His laboratory results, including coagulation testing, were all normal. A ball-like polyp was identified in the descending colon ( Fig. 1 a) and was removed using a snare to leave a $10-\mathrm{mm}$ peduncle. The remaining four small polyps $(\leq 5 \mathrm{~mm})$, located in the sigmoid colon and rectum, were removed using forceps.

The following morning, the patient ascended and descended a staircase for approximately 40 minutes. He later complained of having passed bloody stools, with a volume of approximately $150 \mathrm{~mL}$, 32 hours after the polypectomy. We performed another colonoscopy and found bleeding at the site of the peduncle in the descending colon. Three clips were placed to stop the bleeding ( Fig. 1 b).

Later the same day, 40 hours after polypectomy, the patient again passed bloody stools, so we immediately performed a third colonoscopy. During this procedure we observed an intramural hematoma $(70 \times 50 \times 40 \mathrm{~mm})$ near the site of the peduncle ( Fig.1c) and noted that the surrounding mucosa was ruptured and bleeding. We therefore injected $10 \mathrm{~mL}$ of $1: 2000$ epinephrine into the hematoma and two clips were used to repair the rupture. Following treatment, the hematoma reduced in size and the bleeding ceased ( $\bullet$ Fig. 1d). The patient was kept under observation for 3 days until he passed normal-colored stools.

Significant intramural hematoma can occur in any part of the gastrointestinal tract [1]. The small bowel, particularly the duodenum, is the site most frequently involved; however intramural hematoma of the colon is a relatively rare event [2]. Spontaneous intramural hematomas are often the result of blunt trauma [3]. The typical causes of nontraumatic spontaneous hematoma are blood dyscrasia, anticoagulant therapy, and other hematologic diseases. Intramural hematoma after polypectomy is rarely observed.

\section{Endoscopy_UCTN_Code_CPL_1AJ_2AC}

Competing interests: None

\section{Shaoping Yu, Guangyao Wu, Zongquan Wen, Haiyan Huang}

Department of Gastroenterology, Dongguan Kanghua Hospital, Dongguan City, Guangdong Province, China

\section{References}

1 Lee SH, Lee JH, Park DH et al. Intramural colonic hematoma: complication of anticoagulation with heparin. Gastrointest Endosc 2005; 62: 783-784

2 Liu Y, Yang S, Tong Q. Spontaneous intramural hematoma of colon. Clin Gastroenterol Hepatol 2012; 10: e38

3 Li ZL, Wang ZJ, Han JG. Spontaneous perforation of a rectal hematoma. World J Gastroenterol 2012; 18: $2438-2440$

\section{Bibliography}

Dol http://dx.doi.org/

10.1055/s-0033-1359122

Endoscopy 2014; 46: E46

(c) Georg Thieme Verlag KG

Stuttgart · New York

ISSN 0013-726X

\section{Corresponding author}

\section{Shaoping Yu, MD}

Department of Gastroenterology

Dongguan Kanghua Hospital

1000\# Dongguan Avenue

Dongguan City

Guangdong Province

China

Fax: +86-769-23095553

yushaopingmd@163.com
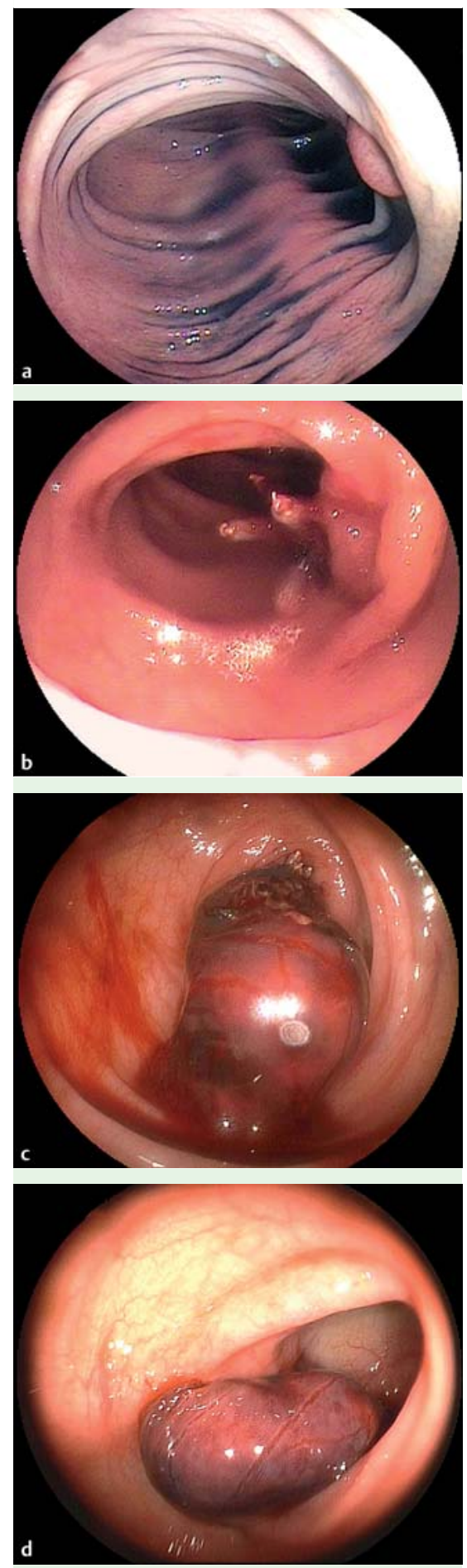

Fig. 1 Colonoscopic views in a 43-year-old man with multiple colonic polyps showing: a a ball-like polyp in the descending colon that was removed using a snare; $\mathbf{b}$ the three clips that were placed on the post-polypectomy peduncle after the patient passed bloody stools 32 hours later; $\mathbf{c}$ the bleeding intramural hematoma $(70 \times 50 \times 40 \mathrm{~mm})$ found near the peduncle during a third colonoscopy that was performed 40 hours after the polypectomy when the patient continued to show evidence of bleeding; $\mathbf{d}$ the hematoma, which had reduced in size and stopped bleeding, following treatment with epinephrine. 